\title{
Isolation, characterization and antimicrobial study of lupeol acetate from the root bark of Fig-Mulberry Sycamore (Ficus sycomorus LINN)
}

\author{
MUKTAR, B;* BELLO, IA; SALLAU, MS \\ Department of Chemistry, Ahmadu Bello University, Zaria, Nigeria \\ *Corresponding author: mbmuktar@yahoo.com +2348172647212
}

\begin{abstract}
The phytochemical investigation of n-butanolic extract from the root bark of Ficus sycomorus using microwave-assisted extraction revealed the presence of steroids, triterpenes, flavonoids, alkaloids, and tannins. Detailed chromatographic techniques on the extract led to the isolation of a triterpenoid compound for the first time from the part of the plant, which was identified as lupeol acetate by chemical and spectroscopic studies. Antimicrobial activity study of the isolated compound on some selected microorganisms showed that the compound is a potential source of antibiotic agents.
\end{abstract}

\section{DOI: https://dx.doi.org/10.4314/jasem.v22i7.21}

Copyright: Copyright (C) 2018 Muktar et al. This is an open access article distributed under the Creative Commons Attribution License (CCL), which permits unrestricted use, distribution, and reproduction in any medium, provided the original work is properly cited.

Dates: Received: 30 May 2018; Revised: 26 July: 2018; Accepted: 27 July 2018

Keywords: Antimicrobial, Ficus sycomorus, lupeol acetate, root bark

Ficus sycomorus is from the largest genus in the Moraceae family commonly known among the Yoruba people as epin and by the Hausa people of Northern Nigeria as Farin Baure (Abubakar et al., 2015; Bwalya, 2014). It is a large, spreading tree up to about $30 \mathrm{~m}$ tall and $30 \mathrm{~m}$ wide and with a thick trunk extending to $3.5 \mathrm{~m}$ in diameter (Bwalya, 2014). This plant is traditionally used for the treatment of epilepsy, diarrhoea, dysentery, urinary tract, vaginal infections, coughs, swollen glands, inflammation, tonsillitis, sore throat, skin rashes, ulcers and tuberculosis (Abubakar et al., 2015; Fowler, 2007). Moreover, it is also claimed that the part of the plant has antiphathologic hemorrhoid activity, M. L. Abdullah (personal communication, March 26, 2017).

The microwave-assisted extraction (MAE), is a novel method that works more favourably with polar solvent and it offers some advantages over conventional extraction methods, such as purity of crude extracts, improved stability, purity and recovery of isolates, reduced processing costs, faster extraction rates, reduced energy and solvent usage (Pare et al., 1994; Patil and Shettigar, 2010). In this paper, the isolation, characterization and antimicrobial study of lupeol acetate from the root bark of Ficus sycomorus is reported for the first time.

\section{MATERIALS AND METHODS}

General experimental procedures: Column chromatography was performed using silica gel (60-
120 mesh), whereas TLC was performed on aluminium plates coated with silica gel $60 \mathrm{~F}_{254}$. The spots were visualized under ultraviolet light (254 and $366 \mathrm{~nm}$ ) and by spraying with $10 \% \mathrm{H}_{2} \mathrm{SO}_{4}$, followed by heating in an oven. The IR spectrum was recorded on a Shimadzu FTIR 400 Spectrometer. The ${ }^{1} \mathrm{H}$ NMR and ${ }^{13} \mathrm{C}$ NMR spectra were recorded on a $600 \mathrm{MHz}$ Bruker AVANCE spectrometer and Suart automatic melting point/SMP40 was used in measuring the melting point.

Plant material: The root bark of Ficus sycomorus was collected around Tsauni Basawa, Samaru-Zaria, in Kaduna State, Nigeria in March, 2017. The plant was authenticated by Namadi Sunusi of the Herbarium unit, Department of Biological Sciences, Ahmadu Bello University Zaria-Nigeria, with the voucher specimen number 1466 . The sample was air-dried and pulverized using a wooden pestle and mortar. The pulverized plant material was then stored in an air-tight polythene bag ready for analysis. The solvents used were of general purpose grade and were redistilled before use.

Preliminary Phytochemical Screening: The crude nbutanol extracts of the root bark of Ficus Sycomarus was subjected to preliminary phytochemical screening of secondary metabolites using standard methods of Evans (2002), Silva et al. (1998) and Sofowora (1993).

Microwave-Assisted Extraction (MAE): The pulverized plant material $(600 \mathrm{~g})$ was divided into five

*Corresponding author: mbmuktar@yahoo.com +2348172647212 
different portions, soaked in n-butanol and allowed to stand overnight. Afterward they were placed in a conventional microwave oven (MATSU M180TC) and microwaved at 3 minutes pulses under low power, removed and allowed to cool. This procedure was repeated 5 times. The microwaved plant material was washed three times exhaustively with the same solvent system. The extract was concentrated by allowing the solvent to evaporate at room temperature to afford a gummy dark red product $(22.0 \mathrm{~g})$.

Isolation and purification: The crude extract was dissolved in chloroform-ethanol (4:1) and the decant so obtained $(15 \mathrm{~g})$ was dried at room temperature. The dried decant $(10 \mathrm{~g})$ was fractionated by open column chromatography with silica gel $(40 \mathrm{~g})$. The elution was started with $100 \%$ n-hexane and $5 \%$ increment of polarity using ethyl acetate was applied after $200 \mathrm{~mL}$ collection. Fraction six was re-fractionated by open column chromatography with silica gel (20 g) and the elution was $100 \%$ n-hexane throughout, for further attempt to separate and isolate components, in $10 \mathrm{~mL}$ per fraction.

Determination of Antimicrobial Activity: The test organisms used for this analysis were clinical isolates of bacteria obtained from the Department of Microbiology, Ahmadu Bello University, Zaria, Nigeria. The isolates were: Escherichia coli, Samonella typhi, Bacillus subtilis and Staphylococcus aureus. Antimicrobial activity was measured using agar well diffusion method according to the National Committee for Clinical Laboratory Standard (NCCLS, 2002).

\section{RESULTS AND DISCUSSION}

Microwave-Assisted Extraction (MAE) and phytochemical analysis: The Finely ground plant materials of the root bark of Ficus sycomorus was extracted using microwave-assisted extraction with nbutanol and the percentage recovery of $3.66 \%$ was calculated. The results of the phytochemical analysis of the part of the plant extract revealed the presence of alkaloids, flavonoids, steroids/triterpenes and tannins, whereas saponins were absent in the extract.

Isolation, purification, characterization and antimicrobial Activity: Two successful silica gel column separation of the n-butanolic extract (MBS) led to the isolation of a compound (MB03), which was identified as lupeol acetate (940 mg) (Figure 1) with the following physical properties, chemical and spectral data:

Physical properties: The compound (MB03) was isolated as an off white powder $(940 \mathrm{mg})$ with melting point of $216-218^{\circ} \mathrm{C}$. The retention factor $\left(\mathrm{R}_{\mathrm{f}}\right)$ of 0.94 was recorded on TLC paper using n-hexane: ethyl acetate (9:1) as solvent system.

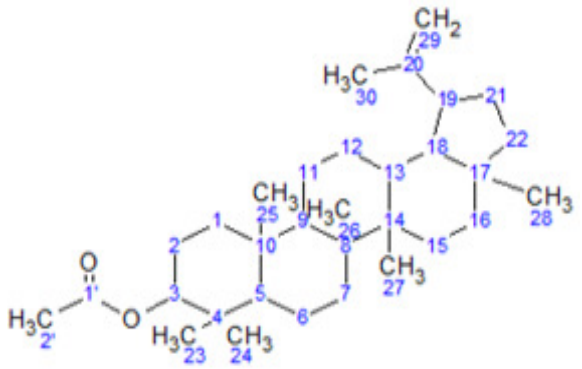

Fig 1: Lupeol acetate

Chemical test on the isolated compound: The isolated compound (MB03) showed a negative result to the Ferric Chloride test and a positive result was observed to the Liebermann-Buchard test (Table 1), thus confirming that the compound is a steroid/triterpenoid type.

Table 1: Chemical test on the isolated compound

\begin{tabular}{clll} 
Tabolate & Test & Result & Inference \\
\hline MB03 & Ferric Chloride test & - & Non -phenolic \\
& Liebermann test & + & Terpenoid/steroid \\
\hline
\end{tabular}

Key: + = positive, $-=$ negative

Spectroscopic analysis: ${ }^{1} \mathbf{H}$ NMR $\left(\mathrm{CDCl}_{3}, 400 \mathrm{MHz}\right)$ : The ${ }^{1} \mathrm{H}$ NMR spectrum (Figure 2) showed eight methyl signals at $\delta \mathrm{H} 2.02,1.66,1.05,0.96,0.85,0.85,0.83$ and $0.78 \mathrm{ppm}$. A doublet of doublets at $\delta \mathrm{H} 4.66$ and $4.54 \mathrm{ppm}$ for $\mathrm{C}-29(2 \mathrm{H}, d d, J=0.60,2.08 \mathrm{~Hz}, \mathrm{H}-29 \mathrm{a}$, $29 \mathrm{~b}$ ), along with that methyl signal at $\delta \mathrm{H} 1.66 \mathrm{ppm}$ for C-30 suggested that the isolated compound (MB03) was a lupane-type triterpenoid. A multiplet at $\delta \mathrm{H} 4.48$ ppm, a characteristic of an $\alpha$-oriented proton at C-3, and a characteristic singlet of methyl $\alpha$-oriented proton at $\delta \mathrm{H} 2.02$ for C-2' suggested that MB03 was an ester derivative of lupeol-type triterpenoid.

${ }^{13} \mathrm{C} \mathrm{NMR}\left(\mathrm{CDCl}_{3}, 100 \mathrm{MHz}\right)$ : The ${ }^{13} \mathrm{C}$ NMR spectrum (Figure 3) further suggested that the isolated compound MB03 was an ester derivative of lupeoltype triterpenoid; a total of 32 carbon signals were observed from the spectrum. There was a carbonyl peak at 171.02 ppm for $\mathrm{C}-1$ ', and a characteristic pair of $\mathrm{sp}^{2}$ hybridized carbon atoms were observed at $\delta$ 151.14 and $109.50 \mathrm{ppm}$ for C-20 and C-29, respectively. Oxygenated carbon shift was observed at $\delta 81.13 \mathrm{ppm}$ for C-3. Consequently, after comparing these NMR data with data in the literature (Rasoanaivo et al., 2014), the compound was assigned to be a known structure (3ß)-Lup-20(29)-en-3-yl acetate, more commonly known as lupeol actate $\left(\mathbf{C}_{\mathbf{3 2}} \mathbf{H}_{52} \mathbf{O}_{2}\right)$. 


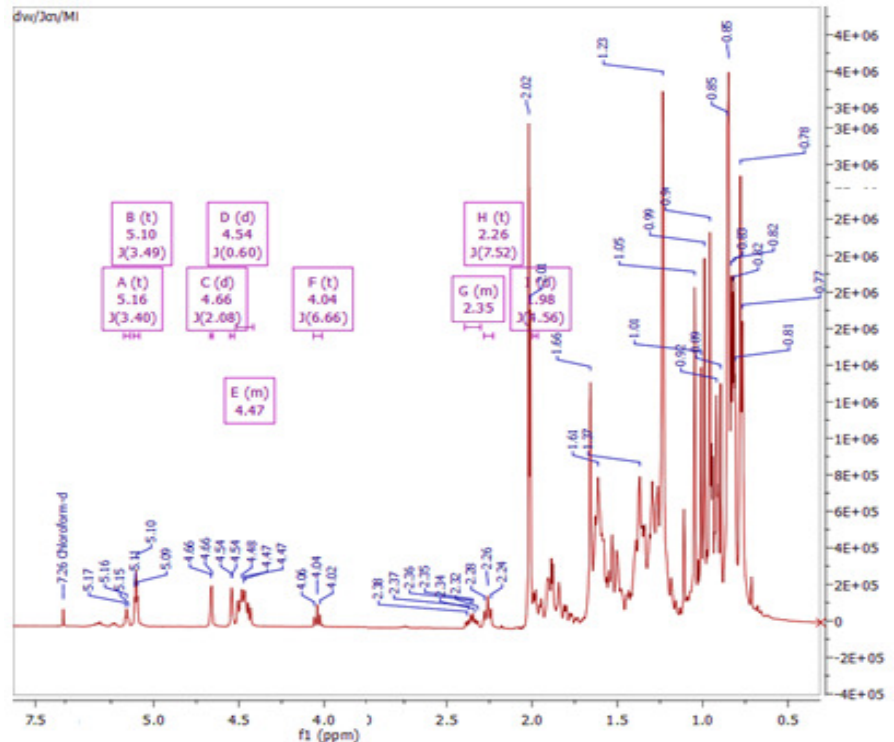

Fig 2: ${ }^{1} \mathrm{H}$ NMR spectrum of lupeol acetate.

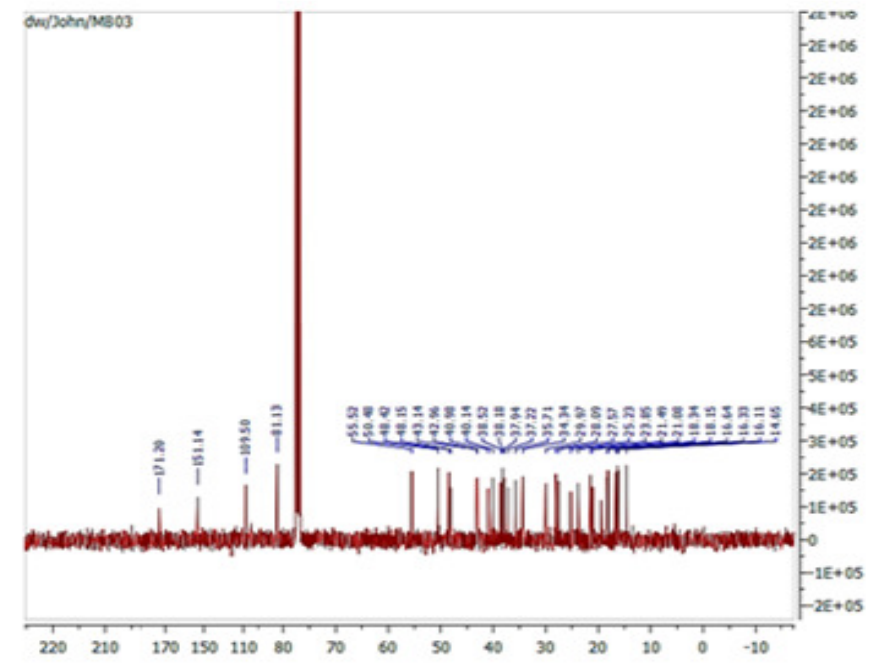

Fig 3: ${ }^{13} \mathrm{C}$ NMR spectrum of lupeol acetate.

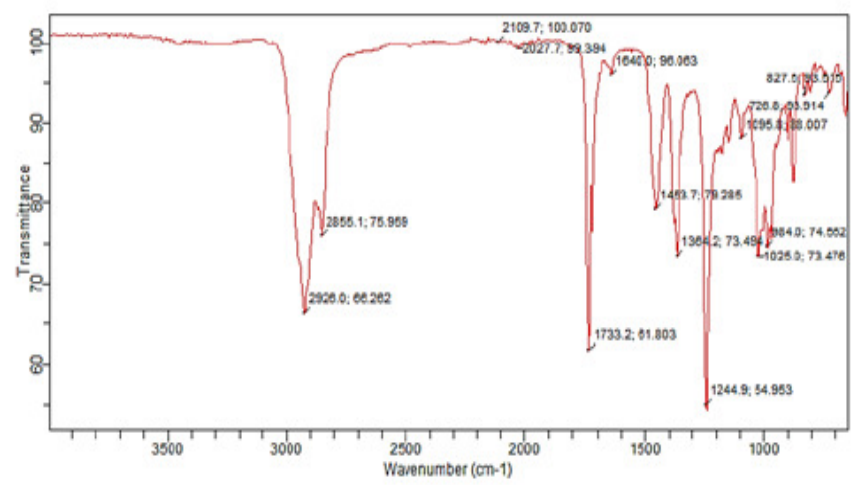

Fig 4: FTIR spectrum of Lupeol acetate.
FTIR: The FTIR spectrum (Figure 4) complemented the NMR assignment; a very sharp carbonyl peak was observed at $1733 \mathrm{~cm}^{-1}$, intense bands at $2929 \mathrm{~cm}^{-1}$ and 2855 $\mathrm{cm}^{-1}$ indicated the stretching of methylene and methyl parts, respectively, a weakly intense band at $1662 \mathrm{~cm}^{-1}$ indicated $\mathrm{C}=\mathrm{C}$ vibrations. The IR absorbance values are in concordance with Silverstein et al. (2014).

Antimicrobial Activity: The dried crude extract and the isolated compound were screened in vitro for various antimicrobial activities against two Gram negative Escherichia coli and Samonella typhi; and two Gram positive Bacillus subtilis and Staphylococcus aureus. Antimicrobial studies (Table 2-4) showed broad spectrum of antimicrobial activity against some tested microorganisms with zone of inhibition values that ranged from $12-15 \mathrm{~mm}$ for the crude extract (MBS) on B. subtilis only with MIC value of $12.5 \mathrm{mg} / \mathrm{mL}$, while the isolated compound (MB03) showed activity against $S$. aureus, $B$. subtilis and $S$. typhi with zone of inhibition values that ranged from $14-18 \mathrm{~mm}$, 12-16 $\mathrm{m}$ and 11-16 $\mathrm{mm}$, respectively, with the corresponding MIC value of $12.5 \mu \mathrm{g} / \mathrm{mL}$.

The presence of lupeol acetate could be the linked to the observed antimicrobial properties in the root bark of the plant, because lupeol acetate have been reported to have antimicrobial, anti-inflammatory, antimalarial and antituberculosis activity (Tahany et al., 2010; Prachayasittikul et al., 2010; Lucetti et al., 2010; Wachter et al., 1999). Medicinal plants are biosynthetic laboratories for different chemical compounds, some of which exert physiological and therapeutic effects (Barthel and Reuter, 1968). The isolated compound (MB03) had more antibacterial activity compare to the crude n-butanolic extract (MBS). 
Table 2: Zones of Inhibition $(\mathrm{mm})$ of the extracts, isolate and standard drug (+ control)

\begin{tabular}{llllll}
\hline \multirow{2}{*}{ Extract/isolate } & & \multicolumn{4}{c}{ zone of inhibition $(\mathrm{mm})$} \\
& Conc. & S. aureus & B. subtilis & E. coli & S. typhi \\
\hline MBS $(\mathrm{mg} / \mathrm{mL})$ & 100 & 0 & 15 & 0 & 0 \\
& 50 & 0 & 14 & 0 & 0 \\
& 25 & 0 & 12 & 0 & 0 \\
MB03 $(\mu \mathrm{g} / \mathrm{mL})$ & 12.5 & 0 & 0 & 0 & 0 \\
& 100 & 18 & 16 & 0 & 16 \\
& 50 & 16 & 14 & 0 & 14 \\
& 25 & 14 & 12 & 0 & 11 \\
Ciprofloxacin $(\mu \mathrm{g} / \mathrm{mL})$ & 30 & 31 & 0 & 0 & 0 \\
\hline
\end{tabular}

Key: MBS = n-butanolic extract MB03= Lupeol acetate

Table 3: Minimum inhibitory concentration (MIC)

\begin{tabular}{lllll}
\hline Extract/isolate & \multicolumn{4}{c}{ Microorganism } \\
& S. aureus & B. subtilis & E.coli & S. typhi \\
\hline MBS $(\mathrm{mg} / \mathrm{mL})$ & ND & 12.5 & ND & ND \\
MB03 $(\mu \mathrm{g} / \mathrm{mL})$ & 12.5 & 12.5 & ND & 12.5 \\
\hline
\end{tabular}

Key: $\mathrm{MBS}=$ n-butanolic extract, $\mathrm{MB} 03=$ Lupeol acetate, $(\#)=$ inhibition observed $\mathrm{ND}=$ not determined.

Table 4: Minimum bactericidal concentration

\begin{tabular}{lcccc} 
Table 4: Minimum bactericidal concentration \\
\hline Extract/isolate & \multicolumn{4}{c}{ Microorganism } \\
& S. aureus & B. subtilis & E. coli & S. typhi \\
\hline MBS $(\mathrm{mg} / \mathrm{mL})$ & ND & 25 & ND & ND \\
MB03 $(\mu \mathrm{g} / \mathrm{mL})$ & 25 & 25 & ND & 25 \\
\hline Key: $\mathrm{MBS}=$ n-butanolic extract, MB03= Lupeol acetate, $(\#)=$ bacteriocidal,
\end{tabular}

Key: $\mathrm{MBS}=$ n-butanolic extract, $\mathrm{MB} 03=$ Lupeol acetate,$(\#)=$ bacteriocidal

$\mathrm{ND}=$ not determined

The sensitivity of these microorganisms to the isolated compound implies that the compound is a potential source of antibiotics agent that can treat infections such as skin, gastrointestinal, urinary tract, respiratory pneumonia, systemic infections and enteric fever (typhoid fever) (Al-Dahmoshi et al., 2013; Bronner, 2004; Podschun and Ullman, 1998). Zone of inhibition values of the isolated compound against the microorganisms which ranged from $11-18 \mathrm{~mm}$ as compared to the standard drugs used as positive control (ciprofloxacin) with zone of inhibition of $26-$ $27 \mathrm{~mm}$ indicates that the isolated compound can be developed further for the fight against these microorganism.

Conclusion: In this study, the presence of lupeol acetate (MB03) in the root bark of $F$. sycomorus has been reported for the first time. The sensitivity of these microorganisms to the isolated compound (MB03) and the MIC values imply that MB03 is a potential source of antibiotic agent. Furthermore, a very simple, reliable and efficient microwave-assisted extraction (MAE) and chromatographic method has also been developed that uses short analysis time and provides an efficient method for routine lupeol acetate isolation.

Acknowledgement: The authors wish to thank Muktar family and family of late Muhammad Yakubu Wanka (Kanawa) for their support financially and morally. The authors are also grateful to the Department of Pure
This could be as a result of the presence of a mixture of numerous chemical compounds with different functional groups and properties in MBS which could exhibit antagonistic interactions among themselves, or the active metabolites would be in small concentrations to exert activity against the tested organisms at the tested concentrations and the experimental conditions. The sensitivity of $B$. subtilis to the isolated compound (MB03) implies that the compound is a potential source of antibiotic agent that can treat infections of the eye, soft tissues, and lung (Ryan and Ray, 2004). MB03 (lupeol acetate) was also active against $\mathrm{S}$. aureus and $S$. typhi with MIC value of 12.5 $\mu \mathrm{g} / \mathrm{mL}$. and Applied Chemistry, University of Strathclyde, Scotland-UK, for NMR analyses.

\section{REFERENCES}

Abubakar, US; Danmalam, UH; Musa, KY; Banni, Z; Yahaya, I; Abba, A; Sani, A (2015). Phytochemical and antimicrobial screening of methanol root bark extract of Ficus sycomorus Linn. Moraceae. Nig. J. Pharm. Sci. 14(2): 1-7.

Al-Dahmoshi, HOM; Naher, HS; Al-Charrakh, AH (2013). Bacteriospermia, first Edition, Lambert Academic Publishing, Germany.

Barthel, A; Reuter, G (1968). Biochemistry and physiology of isoprenoid guanidines, especially (4-hydroxy-3-methyl-2-buten-1-yl) guanidinein Galega officinialis. Pharmazie. 23(1): 26-33.

Bronner, S (2004). Regulation of virulence determinants in staphylococci. Complexity and applications. FEMS Microbiol. Rev. 28: 183-184.

Bwalya, AG (2014). Evaluation of the in vitro biological activities and phytochemical profiling of eight ficus species collected in zambia. Doctoral dissertation, School of Pharmacy, University College London, United Kingdom. 
Evans, WC (2002). Trease and Evans pharmacognosy. Bailliere Tindall, London, United Kingdom.

Fowler, DG (2007). Zambian Plants: their vernacular names and uses. Royal Botanic Gardens, Surrey, United Kingdom.

Lucetti, DL; Lucetti, EC; Bandeira, MAM; Veras, HN; Silva, AH; Leal, LKA; Viana, GB (2010). Antiinflammatory effects and possible mechanism of action of lupeol acetate isolated from Himatanthus drasticus (Mart.) Plumel. J. Inflam. 7(1): 60 .

National Committee for Clinical Laboratory Standards (NCCLS) (2002). Performance Standards for antimicrobial susceptibility testing. 8th Informational supplement. Nat. Comm. Clin. Lab. Stand., Villanova, Pa.

Pare, JJR; Belanger, JMR; Stafford, SS (1994). Microwave-assisted process (MAPTM): a new tool for the analytical laboratory. TrAC Trends Analyt. Chem. 13(4): 176-184.

Patil, PS; Shettigar, R (2010). An advancement of analytical techniques in herbal research. $J$. $A d v$. Sci. Res. 1(1): 08-14.

Podschun, R; Ullman, U (1998). Klebsiella spp. as Nosocomial Pathogens: Epidemiology, Taxonomy, Typing Methods, and Pathogenicity Factors. Clin. Microb. Rev. 11(4): 589-603.

Prachayasittikul, S; Saraban, P; Cherdtrakulkiat, R; Ruchirawat, S; Prachayasittikul, V (2010). New bioactive triterpenoids and antimalarial activity of Diospyros rubra Lec. Excli J . 9(1).
Rasoanaivo, LH; Wadouachi, A; Andriamampianina, TT; Andriamalala, SG; Razafindrakoto, EJB; Raharisololalao, A; Randimbivololona, F (2014). Triterpenes and steroids from the stem bark of Gambeya boiviniana Pierre. J. Pharmacogn. Phytochem. 3(1): 68-72.

Ryan, KJ; Ray, CG (2004). Sherris Medicinal Microbiology. Mcgram Hill, New York.

Silva, GL; Lee, IS; Kinghorn, AD (1998). Special problems with the extraction of plants. In Natural Products Isolation. Humana press Publishers, New Jersy, p. 343-363.

Silverstein, RM; Webster, FX; Kiemle, DJ; Bryce, DL (2014). Spectrometric identification of organic compounds. John wiley \& sons, New Jersey, USA.

Sofowora, EA (1993). Medicinal plants and Traditional medicine in Africa. Spectrum Books, Ibadan, Nigeria.

Tahany, MAR; Hegazy, AK; Sayed, AM; Kabiel, HF; El-Alfy, T; El-Komy, SM (2010). Study on combined antimicrobial activity of some biologically active constituents from wild Moringa peregrina Forssk.J. Yeast Fungal Res. 1(1): 015-024.

Wachter, GA; Valcic S; Flagg ML; Franzblau SG; Montenegro G; Suarez E; Timmermann BN (1999). Antitubercular activity of pentacyclic triterpenoids from plants of Argentina and Chile. Phytomed. 6(5): 341 